\title{
Perspectives on the draft ICH-M10 guidance: an interview with Eric J Woolf
}

\author{
Eric J Woolf*,1 \\ ${ }^{1}$ Merck \& Co., Inc., Pharmacokinetics, Pharmacodynamics \& Drug Metabolism, Regulated Bioanalysis, 770 Sumneytown Pike, \\ WP75B-300, West Point, PA 19486, USA \\ *Author for correspondence: eric_woolf@merck.com
}

Biography: Dr Woolf is currently Executive Director of the regulated PK Bioanalysis Group of Merck Research Laboratories, West Point, PA, USA. He received his BA in Chemistry from LaSalle College in 1982, and a PhD in Analytical Chemistry from Seton Hall University in 1986. From 1986 to 1990, he was a member of the Drug Metabolism/Pharmacokinetics Department of Berlex Laboratories. He joined Merck Research Laboratories in 1990 as a research fellow. Dr Woolf and his group have supported numerous clinical development projects that have led to the successful registration of Merck compounds. Since 1986, he has authored or coauthored over 50 research papers pertaining to bioanalysis and pharmacokinetics.

This interview was conducted by Sankeetha Nadarajah, Managing Commissioning Editor of Bioanalysis, at the AAPS ICH-M10 Public Consultation Workshop (Silver Spring, MD, USA), 11 June 2019.

Accepted for publication: 11 July 2019; Published online: 6 September 2019

Keywords: bioanalytical validation $\bullet \mathrm{ICH} \bullet \mathrm{M} 10$

\section{Can you provide a brief overview of the scope of the draft ICH-M10 guidance?}

The current scope per the draft document is all clinical studies included to make regulatory decisions as well as pivotal pharmacokinetic and toxicokinetic studies. I think this is a point that industry is interested in getting clarification on, so as a result of the discussions within both the EBF meeting and the current AAPS workshop, we are hoping to fine tune the scope to be more specific with respect to eliminating ambiguities in the current language of the document.

\section{Why was there a need for the ICH-M10 guidance when there are already BMV guidances} available?

You hit the nail on the head and the fact being that there are many guidelines documents available from different regulatory authorities. Being in drug development, we are interested in getting our compounds approved in as many geographies as possible, to get drugs to the people all around the world. So that in turn makes us have to be compliant with a multitude of different guidance out there and various instructions, or documentation, or practices accordingly. Hopefully with a single ICH-M10 document, that process will be streamlined and we will be able to develop our drugs and do our bioanalytical work under one harmonized guidance, and will not have to take into account the various nuances that impact our current work stream.

\section{Can you explain how the ICH-M10 guidance will be compiled and industry feedback will be taken into consideration?}

Once the proposal for harmonized guidance was accepted by $\mathrm{ICH}$, an expert working group was assembled consisting of representatives from both industry and regulatory authorities that are partaking of $\mathrm{ICH}$. An assessment and a review of various current regulatory documents was conducted and then the expert working group compiled a draft document taking into account the requirements of the various individual regional documents. This document was then circulated in a closed manner among representatives of the different groups that participate in ICH.

In the USA, the industry groups are from PhRMA as well as the generic drug industry, so members of those organizations commented on the first draft. These were compiled and fed in to the expert working group, and were are taken into account to generate a second draft, which is the draft currently in circulation for public comment. 
The current draft is open to public comment from anyone in the industry. Various industry groups, such as IQ, AAPS, EBF and so on, are providing feedback to the draft document in a consolidated manner. Other companies will be providing individual feedback and all this feedback will be reviewed by the expert working group and should be taken into account in preparation of the final document that will then be ratified by the ICH parties.

\section{Are there any disadvantages of such a collective consensus guidance?}

I think the disadvantages are that we lose science in the guidance and start playing give and take with respect to specific validation assessments that one regulatory agency may favor, and which another agency may be ambivalent toward, and alike. So rather than assessing the scientific validity of these assessments, for example, regulator from Country A says to regulator from Country B, you can put in your requirements regarding X as long as you accept our requirement regarding $Y$ ', so you lose the science and start building into more of a compilation of regulations as opposed to a scientifically driven regulation.

\section{What will happen to existing BMV guidance currently followed by the industry such, for example, the US FDA and European Medicines Agency (EMA) guidance?}

It is our understanding that the ICH guidance will supersede existing local guidance and those guidance will no longer be applicable in line of the gratification of the ICH document.

\section{Disclaimer}

The opinions expressed in this interview are those of the interviewee and do not necessarily reflect the views of Newlands Press Ltd. or Merck \& Co.

Financial \& competing interests disclosure

EJ Woolf is an employee of Merck \& Co. The interviewee has no other relevant affiliations or financial involvement with any organization or entity with a financial interest in or financial conflict with the subject matter or materials discussed in the manuscript apart from those disclosed.

No writing assistance was utilized in the production of this manuscript. 